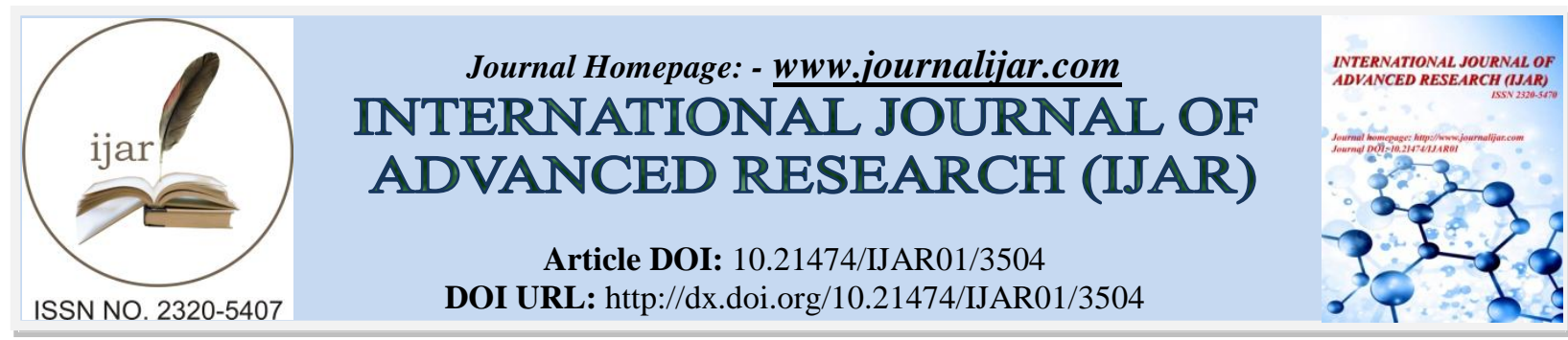

RESEARCH ARTICLE

\title{
EFFICIENCY OF SYSTEMIC VERSUS INTRALESIONAL INJECTION OF BONE MARROW CELLS ON BUCCAL WOUND HEALING IN DIABETIC RATS.
}

Fatma Ibrahim Elfaiedi ${ }^{1}$, Mona E. Denewar ${ }^{2}$ and Fatma M. M. Ibrahim ${ }^{3}$.

1. Teaching assistant, Faculty of Dentistry, Sirte University, Libya.

2. Lecturer of oral biology Mansoura University, Mansoura, Egypt.

3. Professor of oral biology, Mansoura University, Mansoura, Egypt.

\section{Manuscript Info}

Manuscript History

Received: 16 January 2017

Final Accepted: 17 February 2017

Published: March 2017

Key words:-

Diabetic wound, PCNA, Bone marrow cells.

\begin{abstract}
The multipotent capability of bone marrow cells gave an impelling reason to study the effect of bone marrow cells in diabetic wound healing. Diabetes is characterized by delayed and poor wound healing. The goal of this study was to evaluate the efficiency of systemic versus intralesional injection of bone marrow cells on buccal wound healing in diabetic rats. Sixty four adult male albino rats were used in the study and divided randomly into four groups. All groups were subjected to buccal wound induction. Group I; non-diabetic group (negative control) and group II; diabetic group (positive control) and did not receive any treatment. The groups III and IV diabetic groups received intralesional and intravenous injection of whole bone marrow cells respectively two days following wound induction. Specimens were obtained after 3, 7 and 12days following wound induction and were processed to be immunostained with mouse monoclonal antibody PCNA. Immunohistochemical results revealed marked expression of PCNA in treated groups III and IV at day 3 compared to non-treated groups I and II, although there was no significant difference between the treated groups. Our results reported that intralesional injection of whole bone marrow cells showed faster healing than intravenous injection and display a more mature histology. In conclusion, Injection of the whole BMCs intralesional is more efficient compared to intravenous route in accelerating the diabetic oral wound closure and enhancing the wound healing quality. The use of whole bone marrow cells appears to be beneficial in the treatment of diabetic oral wounds.
\end{abstract}

Copy Right, IJAR, 2017,. All rights reserved.

\section{Introduction:-}

Diabetes is the disease that compromises the body's ability to heal wounds and injuries. Wound healing in diabetic patients is a complex and multifactorial process due to dysregulated molecular interactions and signal transductions that delay wound healing(Fekrazadet al., 2015).Diabetic patients may have problem in the process of wound healing because they suffer from impaired vascularization, anti-inflammatory and antioxidant response, damage from reactive oxygen species and advanced glycation end products. Moreover, growth factor production and 
collagen synthesis are impaired in diabetes (Brem and Tomic-Canic, 2007;Enoch et al., 2008; YadollahDamavandi et al., 2015).In dental sciences, the issue of delayed healing of oral wounds and periodontal lesions in diabetic patients has raised great controversy. The delayed healing may cause pain, infection, discomfort and even affect the prognosis of the patient, leading to the failure of the treatment and the need for repeated therapies (Fekrazadet al., 2015).Optimum healing of oral wound requires a well-orchestrated integration of the complex biological and molecular events of cell migration and proliferation.

Extending the hypothesis that cell therapy may be required to recondition chronic wounds and accelerate their healing leads to the conclusion that bone marrow cells may offer even greater advantages. Previous studies demonstrated that re-epithelialized mucosa of grossly "regeneration" experimental ulcers has prominent histological and ultrastructural abnormalities: Reduced height, increased connective tissue and a disorganized microvascular network. These prominent abnormalities may interfere with the mucosal defense and cause ulcer recurrence when ulcerogenic factors are present. Therefore, the quality of mucosal structural restoration may be the most important factor in determining the future ulcer recurrence (Tarnawski et al., 1990; Tarnawski et al., 1991). In some situations, such as for chronic non-healing wounds, the objective of cellular therapy is to reverse those cellular and vascular events that compromise repair (McFarlin et al., 2006; Dash et al., 2009).

Whole bone marrow cells (BMCs) participate in tissue repair processes and may have a role in wound healing. One role based on the capacity of bone marrow cells to secrete a variety of growth factors and cytokines that are required to orchestrate tissue repair and regeneration. This mechanism would regulate cellular processes such as chemotaxis, cell proliferation, angiogenesis, extracellular matrix production and remodeling. Another role for bone marrow derived cells is to differentiate into multiple cell types including fibroblast and myofibroblasts after migrating to the injury site (Yamaguchi et al., 2005). A recent study has shown that whole bone marrow is more efficient compared to bone marrow cultured cell and mesenchymal stem cell in reducing wound size in a murine model of delayed wound healing. They demonstrate that mixed bone marrow cell preparations may be superior to more purified stem cell formulation in stimulating wound healing (Rodriguez-Menocal et al., 2015).

Currently, there are two basic delivery methods: Systemic infusion of cells into the vascular circulation and direct application of therapeutic cells to wound sites (Sorrell and Caplan, 2010).Therefore the purpose of this study was directed toward the comparison of the efficacy of systemic versus intralesional injection of whole BMCs in regeneration of diabetic oral wound.

\section{Material and methods:-}

Sixty-four adult male Albino rats weighing (200-250g) were used in this study; they were housed in the laboratory of Nile Center for Experimental Researches under controlled condition, with constant temperature and humidity. Animals were divided randomly into four groups $(\mathrm{n}=16)$.

Group I (negative control): subjected to buccal wound followed by injection of Hank's balanced salt solution (HBBS)/bovin serum albumin after two days. Group II (positive control): induced for experimental diabetes, subjected to buccal wound after one week of diabetic induction followed by injection of (HBBS)/bovin serum albumin after two days. Group III: subjected to experimental diabetes and buccal wound followed by intralesional injection of $1 \times 10^{6}$ suspended in HBBS/bovine serum albumin of bone marrow cells after two days. Group IV: subjected to same procedure in group III and received Intravenous injection of $1 \times 10^{6}$ of bone marrow cells suspended in HBBS/bovine serum albumin of bone marrow cells after two days.

\section{Streptozocin- induced diabetes:-}

Diabetes was successfully induced in rats of groups II, III, IV, via single intraperitoneal injection of freshly prepared streptozotocin (STZ) (Sigma, St. Louis, MO, USA) dissolved in $0.1 \mathrm{ml}$ citrate buffer ( $\mathrm{pH} 4.5$ ) at a dose of $45 \mathrm{mg} / \mathrm{kg}$ as described previously (Rajasekar et al ., 2014). Diabetes was assessed by measuring the blood glucose level in rat's tail blood using a glucometer (B. Braun, Seoul, Korea) 7days after injection of STZ. Rats whose blood glucose level exceeded $300 \mathrm{mg} / \mathrm{dl}$ were considered diabetic and were included in this study (Hie et al., 2007). Serum blood glucose was checked daily using ACCU-check advantage strips and lunit of Insulin therapy was administered if the animal had high glucose readings. High glucose reading were indicated on the glucometer as high (O'Loughlin et al., 2013). 


\section{Wound induction:-}

All rats were anesthetized with $30 \mathrm{mg} / \mathrm{kg}$ ketamine and $10 \mathrm{mg} / \mathrm{kg}$ xylacine intraperiotoneally (Fekrazad et al., 2015). Wound measuring $4 \mathrm{~mm}$ in diameter was made at buccal mucosa opposite to molar teeth midway between mandibular and maxillary teeth using a standard punch biopsy technique. The day of wound induction was considered as day zero.

\section{Isolation of whole BMCs:-}

Bone marrow was harvested from albino rats weighing (100-140g).In order to prevent diabetic cellular dysfunction (because of glycosylation and other mechanisms) from adversely affecting wound healing, we isolated the BMCs from non-diabetic albino rats (Lin et al., 2008). Briefly, the rat BMCs were flushed from tibias and femurs with cold HBSS and $0.5 \%$ bovine serum albumin. The suspension was then strained through a 70- $\mu$ m nylon filter and washed twice with HBSS/bovine serum albumin. The concentration of the cells was adjusted to $10^{5}$ viable cells/ $\mu$ l. The viability of BMCs was checked using Trypan Blue with an average of 95\% viability before injection. Cell-free extract was prepared by subjecting the BMCs to three freeze-thaw cycles using an ethanol/dry ice bath, followed by microcentrifugation at 14,000 rpm to remove insoluble material (Yeghiazarians et al., 2009).

\section{Bone marrow cells transplantation:-}

Two days after wound creation, all rats were anesthetized and treated as follow: rats of Group III $(n=16)$ were treated once by intralesional injection (at two points around the wound) of $1 \times 10^{6} \mathrm{BMCs}$ suspended in $10 \mu 1$ HBSS/bovine serum albumin; rats of group IV $(n=16)$ were treated once by intravenous injection via tail vein with BMCs at a dose of $1 \times 10^{6} / 10 \mu 1 \mathrm{HBSS} /$ bovine serum albumin (Yeghiazarians et al., 2009), while rats of groups I $(\mathrm{n}=16)$ and group II $(\mathrm{n}=16)$ were received $10 \mu \mathrm{lHBSS} /$ bovine serum albumin only.

\section{Tissue preparation:-}

Following sacrifices of rats at 3,7and12 days post wounding, tissue specimen containing the wound was dissected out from each rat, fixed in a $10 \%$ buffered formalin solution and paraffin embedded, sectioned into $4 \mu \mathrm{m}$-thick slice and prepared for routine hematoxylin and Eosin staining and immunohistchemical staining.

\section{Immunohistochemical analysis:-}

Immunohistochemistry was performed using mouse monoclonal antibody PCNA as a cell proliferation marker (Thermo Scientific, Fremont, USA). Each slide was screened microscopically and the area with the most intense PCNA staining were selected for quantification. Slides were photographed using Olympus ${ }^{\circledR}$ digital camera installed on Olympus ${ }^{\circledR}$ microscope with $1 / 2 \mathrm{X}$ photo adaptor, using $40 \mathrm{X}$ objective. The resulted images were analyzed on Intel ${ }^{\circledR}$ Core I $3{ }^{\circledR}$ based computer using Video Test Morphology ${ }^{\circledR}$ software (Russia) with a specific built-in routine for immunohistostain analysis and stain quantification. Five images for each slide were taken for analysis.

\section{Statistical analysis:-}

Data analyses were performed using IBM Statistical Package for Social Sciences (SPSS) software package version 20.0. The description of data presented in the form means (+/-) standard deviation (SD) for quantitative data. The statistical comparison between the different groups and the significance of difference was tested using one way ANOVA and repeated measure ANOVA tests followed by Post Hoc test for pairwise comparisons.

\section{Results:-}

\section{Histological analysis:-}

Examination of H\&E stained sections of Group I showed wound area filled with granulation tissue, intense inflammatory cells infiltration and disorganization of the epithelium with mitotic activity at the wound edges at day 3(Fig.1A) while in group II showed less mitotic figures than group I (Fig.1B). In comparison to group III and group IV, the epithelia showed increase in mitotic activity (Fig.1C, D). At day 7; group I revealed moderate inflammatory cells infiltration in the granulation tissue and more mitotic activity in the epithelial edges compared to day 3(Fig.1E) while Group II showed intense inflammatory cells infiltration in the granulation tissue with less mitotic activity within the epithelium (Fig.1F). Group III showed advanced healing process. The wound area was covered with epithelia with little irregularity in the basement membrane and the lamina propria reveled well-formed new blood vessels (Fig.1G). Group IV revealed epithelial migration into the wound bed and the epithelial cells showed mitotic activity (Fig.1H).At day 12; the wound area in group I was covered by thin epithelium with irregular basement membrane and shallow rete ridges. Lamina propria showed newly formed blood vessels with few inflammatory cells infiltration (Fig.1I) while in Group II, the granulation tissues showed intense inflammatory cells infiltration and the 
Epithelia at the wound edges showed increase in the mitotic activity (Fig.1J). The epithelium showed marked reepithelization and complete healing with obvious mitotic figure in group III (Fig. $1 \mathrm{~K}$ ). However, the wound area covered with thinner epithelium in group IV (Fig.1L).

\section{Immunohistochemical observations:-}

The expression pf PCNA was detected within the epithelial cells;

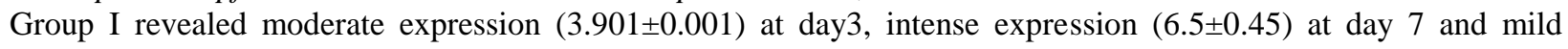
expression (2.4 \pm 0.84$)$ at day 12 . Group II revealed moderate expression (3.8 \pm 0.82$)$ at day 3 whichincreased slightly at day $7(4.2 \pm 1.03)$ while showed mild expression at day $12(2.8 \pm 0.68)$. Group III showed intense expression (7.2 \pm

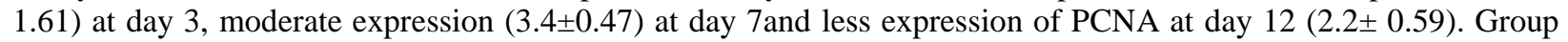
IV showed intense expression $(6.068 \pm 0.824)$ at day 3 which began to decrease at day $7(4.2 \pm 1.06)$ and became less at day 12 (3.4 0.51$)$. (Fig. 2)

\section{Statistical analysis results:-}

Descriptive statistics of the PCNA expression were represented by the mean \pm SD for all groups. The highest mean value was in group III at day 3. One way ANOVA followed by Post Hoc test revealed statistical significant difference between the different groups represented in table 1 and Figure 3.

Repeated measures ANOVA revealed significant difference among different days in group II, III and IV ( $p<0.05$ ) while a highly significant difference in group I $(\mathrm{p}=0.005)$. (Fig.4)

\section{Discussion:-}

Cell therapy has come into attention in all medical fields as a new paradigm for future medicine. Whole bone marrow cells participate in tissue repair processes and may have a role in wound healing. Wound healing is a complex process that is regulated by cytokines and growth factors and modulated by systemic conditions such as diabetes (Rai et al., 2005). A serious complication of diabetes is impaired healing. Optimum healing of oral wound requires a well-orchestrated integration of the complex biological and molecular events of cell migration and proliferation. When the normal biological process fails for any reason, this healing process can stall resulting in chronic wounds (Giles et al., 2015).

Siqueira et al., 2010 stated that a critical component of a vigorous healing response is a generation of a sufficient number of cells to participate in repair. Recently, Garget al., 2014 has been reported that BMCs could home to site of injury or inflammation, play a direct role in vasculogenesis and modulate epithelial regeneration. A current problem is the development of strategies that ensure that these cells reach wound beds in a timely fashion and in sufficient numbers to maximize their therapeutic benefits. The aim of our study was directed toward the comparison of the efficacy of systemic versus intralesional BMCs in regeneration of diabetic oral wound.

In the present study, STZ induced diabetic rats were used as a model to study the healing efficiency of bone marrow cells. The significance of diabetes is that delayed wound healing and thus, acceleration of healing is crucial in oral and maxillofacial surgery. Rees \& Alcolado, 2005 stated that STZ induced diabetes in rodents is considered to be a model of insulin-dependent diabetes mellitus and is widely used in the study of insulinopenia and hyperglycemia. Also, Papaccio et al., 2000 reported that STZ selectively destroys beta cells, inhibits the synthesis and release of insulin and causes the onset of diabetes mellitus.

A study done by Roriguez-Menocal et al., 2015 demonstrated that the whole BMCs appeared to stimulate a greater healing response than bone marrow mesenchymal stem cells in a radiation induced delayed wound healing animal model. The whole BMCs have a greater mixed population of cell types thus they was capable of producing a more wide-ranging cytokine profile that more closely resembled that seen in healing wounds. The results of the previous study support the use of a mixture of cells types in designing clinical approaches to wound healing. Based on the previous statement, the whole BMCs were used in the present study.

In hematoxylin and eosin results the wound area in group I (negative group), at day 7 showed slight proliferation of covering epithelia with moderate inflammatory cells infiltration within granulation tissue while after 12 days the wound area was covered by thin epithelium which showed irregular basement membrane and shallow rete ridges. These results are consistent with Karavana et al., 2011 who reported that oral mucosal ulceration in animal model showed complete healing on the $12^{\text {th }}$ day post ulceration. 
In the present study, the results in group II (positive group) at day 3showed prolonged excessive inflammatory cells infiltration, loss of attachment and decreased mitotic activity within epithelia and connective tissue. This is in accordance with You \& Han, 2014 who reported that one of main contributing factors for the non- or delayed healing wound is decreased function (mitotic activity, extracellular matrix and growth factors synthesis) of the key cells for wound healing including fibroblast and keratinocytes. Therefore, the wound remains open for long period of time which leads to infection.

The wound area in Group III (intralesional group) at day 3, showed granulation tissue formation with dense inflammatory cells infiltration, increased dilated blood vessel and mitotic activity increased at the epithelial edges of the wound, while at day 7, the wound area was covered with epithelia. These results are in many respects to those of Lin et al., 2008 who demonstrated that topical subcutaneous transferring bone marrow progenitor cells into full thickness excisional dorsal cutaneous wound in diabetic mice significantly improves diabetic wound healing. The authors hypothesized that these progenitor cells will differentiate into endothelial cells, increase wound vascularity and improve wound healing.

The wound area in group IV (intravenous group), at day7 was partially covered by epithelium, while at day 12 healing process was evident and the wound area covered with thin epithelia. This is in agreement with RoriguezMenocal et al., 2015 who explained that whole BMCs were able to achieve higher new blood vessel formation because it stimulates endothelial cells and angiogenesis in tissue repair.

Detection of proliferating cells in tissue sections can be achieved by a number of methods, Hall \& Woods, 1990 and Muskhelishvili et al., 2003 reported that immunohistochemical methods of assessing cell proliferation have particular advantages over the other techniques because of maintenance of cellular and tissue architecture, the relative simplicity of methodology and rapidity of results. In order to identify the efficiency of intralesional and intravenous injection of BMCs on cellular proliferation, PCNA was used as a cell proliferation marker.

In the current study, PCNA expression appeared obvious mainly in basal cell layer of all groups. This result could be explained by Ishii et al., 2014 who mentioned that the cells proliferation occurs principally in the basal layer of the epithelium in which keratinocytes undergo terminal differentiation as they migrate to the surface. Also, Yue et al., 2005 stated that the basal layer of the stratified squamous epithelium consists of a heterogenous population of proliferative and differentiating cells.

In addition, PCNA expression was obvious in the marginal epithelia in group III and group IV, at day 3 specifically, (7.2 \pm 1.61 and $6.068 \pm 0.824)$ respectively. These findings imply that the wound healing is provoked not only by the proliferation and differentiation of basal cells but also by supplying cells from the wound margin to the epithelial outgrowth as mentioned by Takaichi et al., 2014.

In group II, there was moderate expression of PCNA at day 3 and 7 days $(3.8 \pm 0.82$ and $4.2 \pm 1.03)$ respectively while mild expression at day 12 (2.8 \pm 0.68$)$. This is consistent with Mclaughlin et al., 2013 who reported that initial delays in cell proliferation following wounding in diabetic rats were related to changes in DNA synthesis rates in basal epithelial cell layers.

In the present study, immunohistochemical results showed marked expression of PCNA in groups III and IV (treated groups) after 3 days (7.2 \pm 1.61 and 6.068 \pm 0.824$)$ respectively compared to groups I and II (non-treated groups) (3.901 \pm 0.001 and 3.8 \pm 0.82 ), although there was no significant difference between treated groups. These findings is in agreement with Isakson et al., 2015 who mentioned that both topical and systemic delivery methods have been shown to be effective in chronic wound healing. Moreover, these results are in analogues in many respects to those of Borue et al., 2004 who found that transplantation of whole bone marrow cells in wound environment, allow the progenitor cells enter the wound area and fuse with the damaged epithelial cells, thereby taking on keratinocytes properties.

Also, these results are supported by the findings of Paradells et al., 2015 who mentioned that BMCs could help to enhance local endogenous proliferation and probably stimulate proliferation and subsequent migration from surrounding zones. Moreover, Rodriguez-Menocal et al., 2015 reported that the whole bone marrow cells were able to achieve higher new blood vessel formation compared with mesenchymal stem cells. This implies a potential significant advantage for whole bone marrow to stimulate endothelial cells and angiogenesis in tissue repair. 
To date, experimental studies have not presented definite answers regarding the role of BMCs and related mechanisms. However, several hypotheses have been proposed. First, Liu et al.., 2006 and M. Isakson et al., 2015 stated that BMCs have the capacity to secrete a variety of growth factors and cytokines. The production of growth factors by BMCs potentially plays a role in coordinating and regulating the cellular processes, such as chemotaxis, inflammation, cell proliferation, tissue granulation, and wound remodeling whichare critical for the efficient wound healing. In addition to the cells themselves participating in the process of wound healing, ultimately differentiating into the cell types required for closure of the wound. Second possibility relates to the tremendous plasticity and the ability of BMCs to differentiate into a variety of cell types and integrate into tissues. Therefore, BMCs may facilitate wound healing as mentioned by Liu et al., 2006. Third, Vaananen, 2005; Aly et al.,2014 mentioned that BMCs release paracrine factors and thereby induce the proliferation of specific cells in the damaged tissue or contribute to making the microenvironment more appropriate for the repair of injury by maximally inhibiting the tissue injury.

In the present study, group III (Intralesional injection) showed faster healing and more organized re-epithelization than group IV (intravenous injection) although there was no significant difference between the two groups in PCNA expression. These results is consistent with Kwon et al., 2008 who attributed that the differences in efficacy of systemic versus local BMCs therapy in wound healing, to the decrease in number of BMCs migrating to the wound after systemic administration. Also, he thought that the decrease in migration of BMCs to the wound treated systematically may due to arterial-venous shunts in diabetic skin. In addition, Karp \& Leng, 2009 stated that during vascular transit, BMCs risk being taken out of circulation, and going to other organs such as the lungs, spleen and liver.This may reduce the numbers of cells that finally appear at a target sites.

Another study done by Sorrell \& Caplan, 2010 revealed that the topical delivery of cells allows for concentrated doses of cells to be delivered to a wound and not become trapped in other sites in the body. Also, it was hypothesized by Chung et al., 2011 that applying cells topically may promote neovascularization from inside the wound not only from the wound periphery.

All of these findings demonstrated that BMCs can contribute to wound repair in diabetic rats and may provide the cell source for regenerative therapy. Despite the current limitations to widespread clinical use, BMCs are highly promising cell sources for the treatment of diabetic wounds either via intravenous or intralesional route. However, further studies are necessary to study the critical factors that make up the microenvironment that supports the survival and differentiation of these cells.

\section{Conclusion:-}

Our findings proposed the intralesional injection of BMCs directly to improve the healing of oral diabetic wound, in an attempt to overcome both decrease in number of BMCs and impaired homing to the site of wound via intravenous route. 


\section{Day 3}

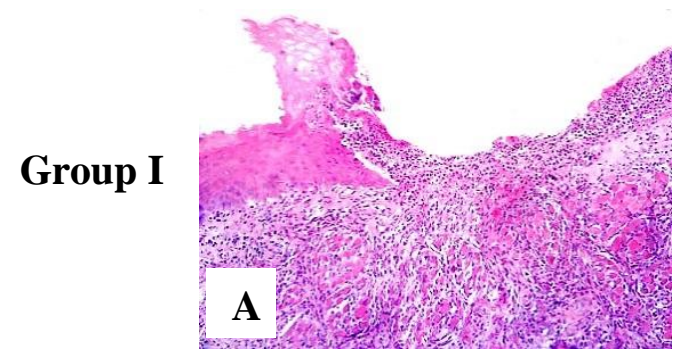

Group II
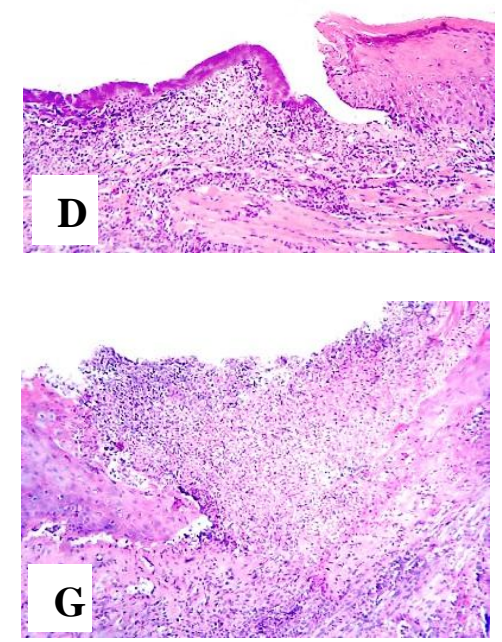

Group III

\section{Group IV}

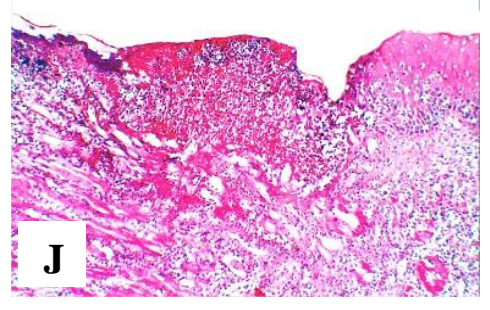

Day 7
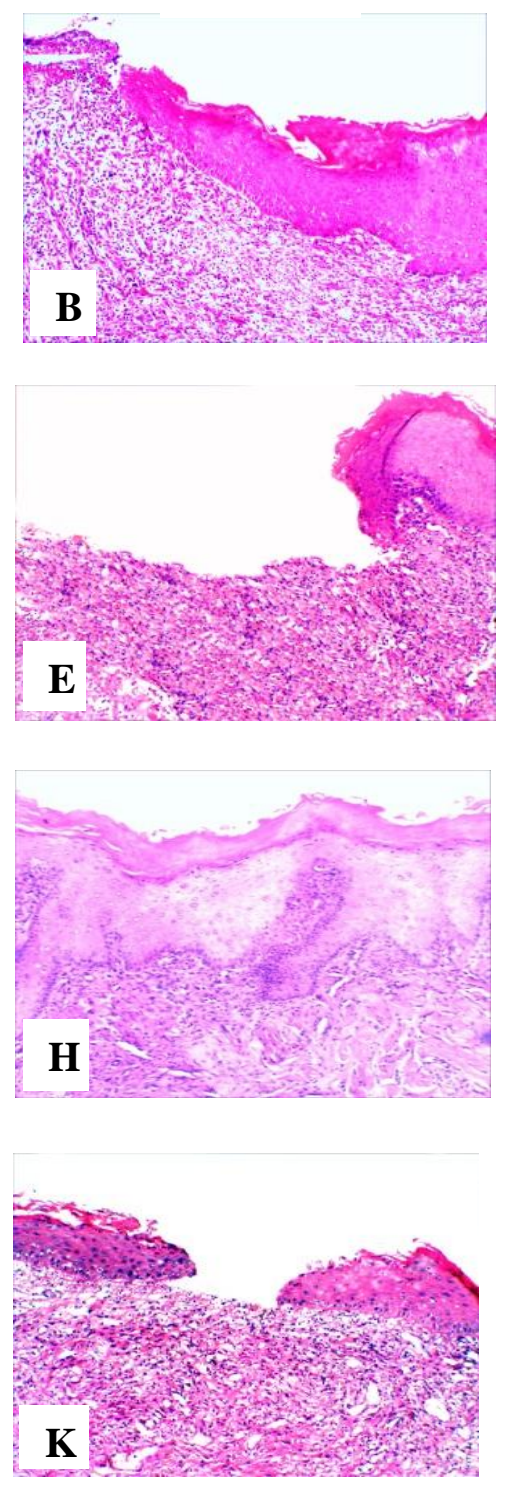

Day 12
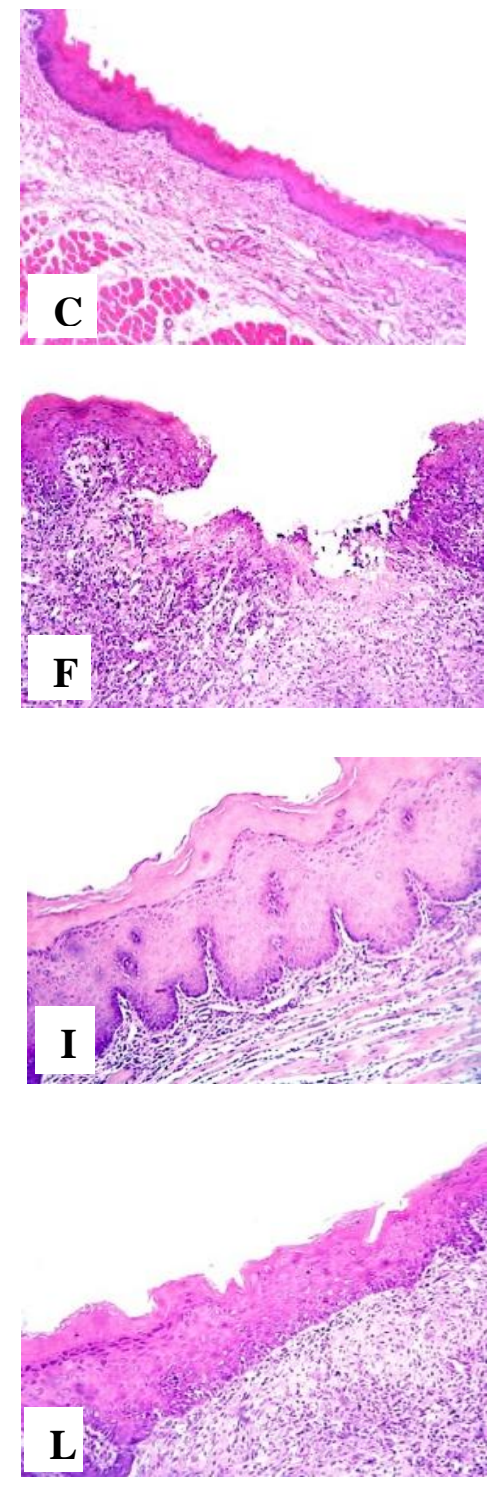

Figure 1. Histological observations of oral mucosa sections in different studied groups (I, II, III and IV) at day3, 7 and 12 (H\&EX100). At day 3shows the wound area filled with granulation tissue with intense inflammatory cells infiltration (A, G and J), moderate inflammatory cells in (D). At day 7 shows slight proliferation of covering epithelium (B), intense inflammatory cells infiltration within the granulation tissue (E),epithelium covering wound area with irregular basement membrane and fibrous lamina propria $(\mathrm{H})$,epithelial migration of wound edges and granulation tissue with moderate inflammatory cells infiltration (K). At day 12 shows thin epithelium with irregular basement membrane covering the wound areaover fibrous lamina propria(C), discontinuity of the epithelium with intense infiltration of inflammatory cells $(\mathrm{F})$, marked epithelization with deep rete ridges and initial organization of collagen fibers in the underlying connective tissue (I), thin epithelium covering wound area with short rete ridges (L). 


\section{Day 3}

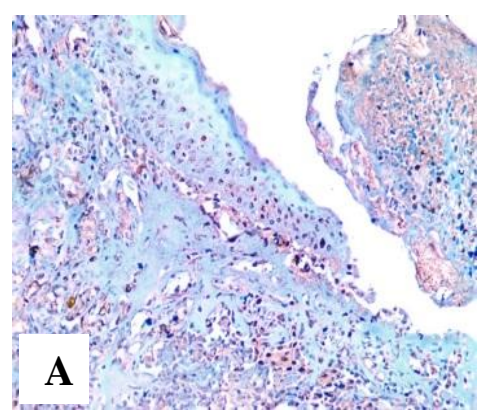

Group I

Group II

Group III
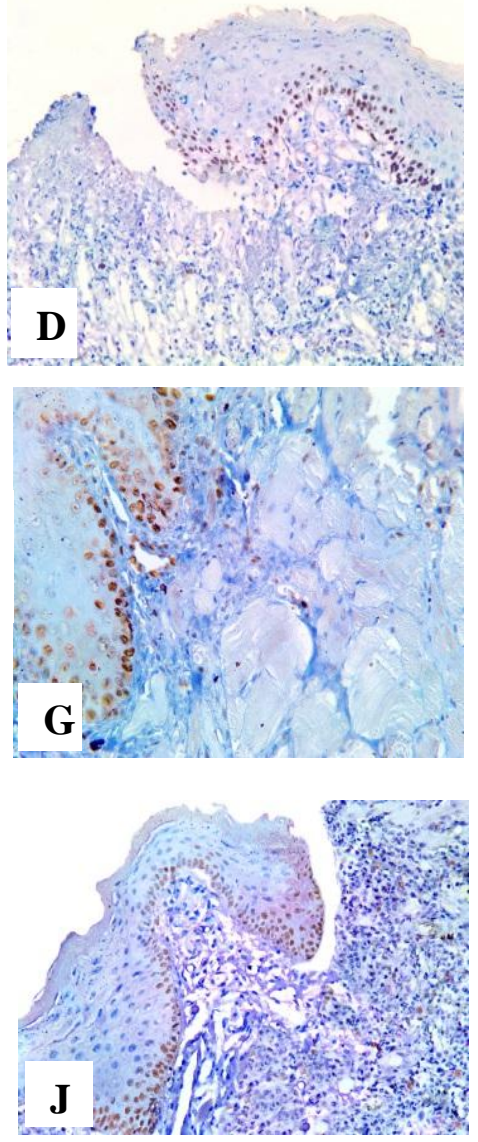

Day 7
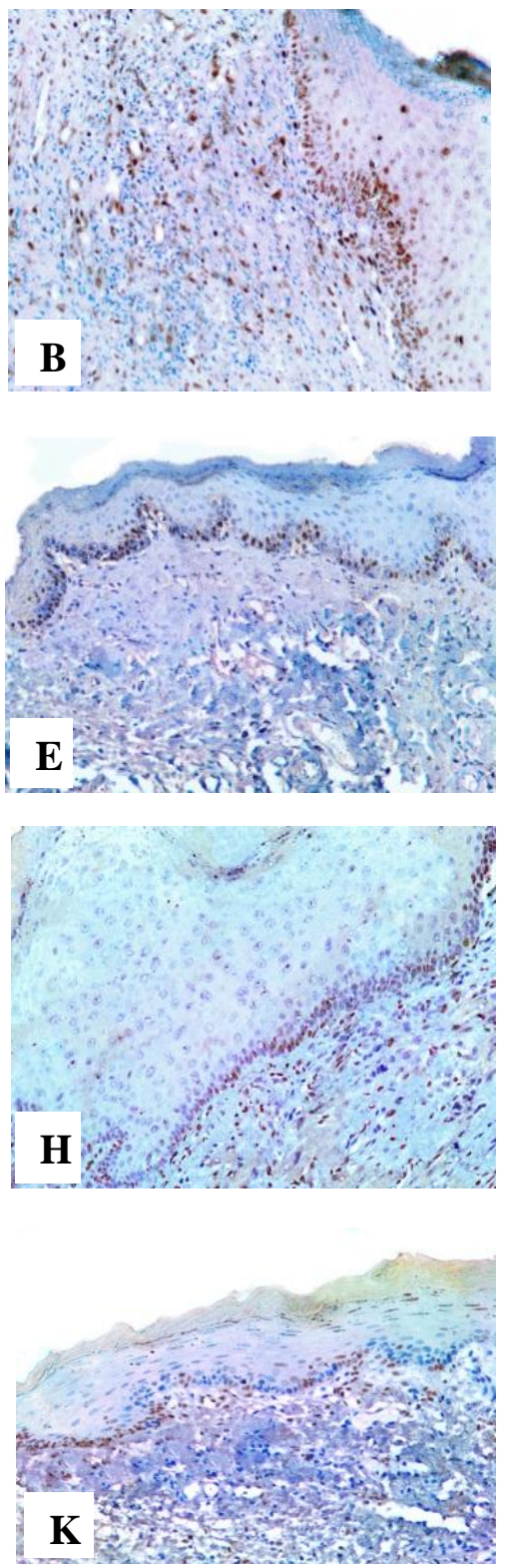

Day 12
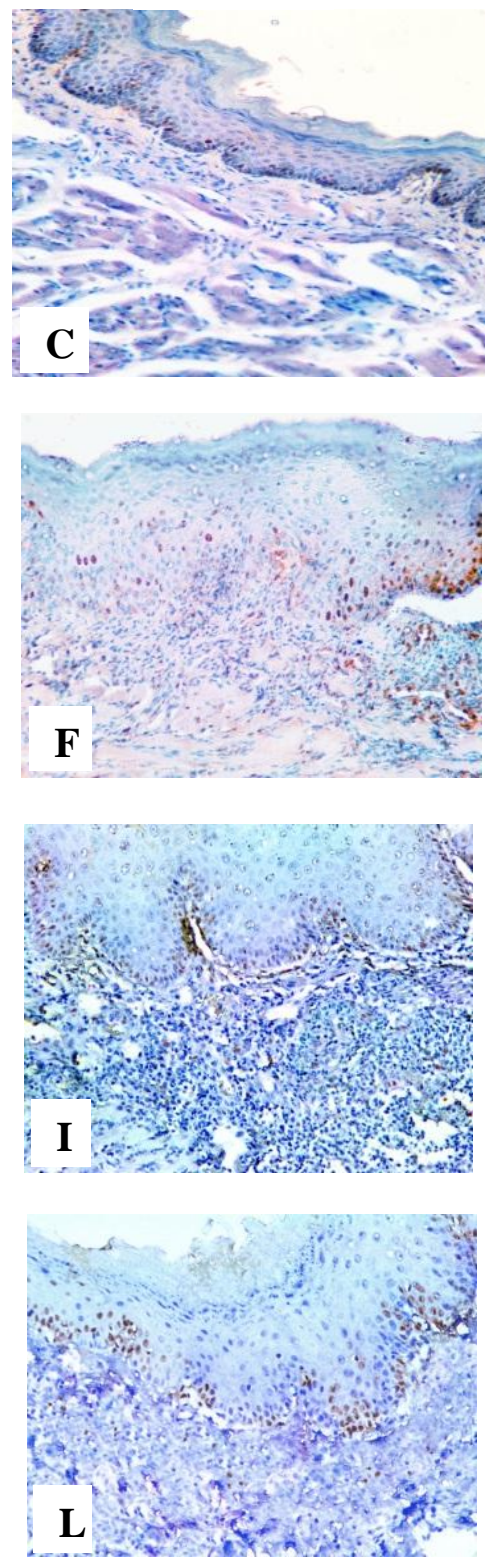

Figure 2.Immunohistochemical expression of PCNA during wound healing in different studied groups (I,II,III and IV) at day 3, 7 and 12 ( IHC staining, PCNA X200).At day 3 shows moderate expression in group I and II (A, D) and intense expression in group III and IV (G, J).At day 7shows moderate expression in group II, III and IV (E, H, $\mathrm{K}$ ) and intense expression in group I (B).At day 12shows mild expression in all studies groups (C, F, I, L) 

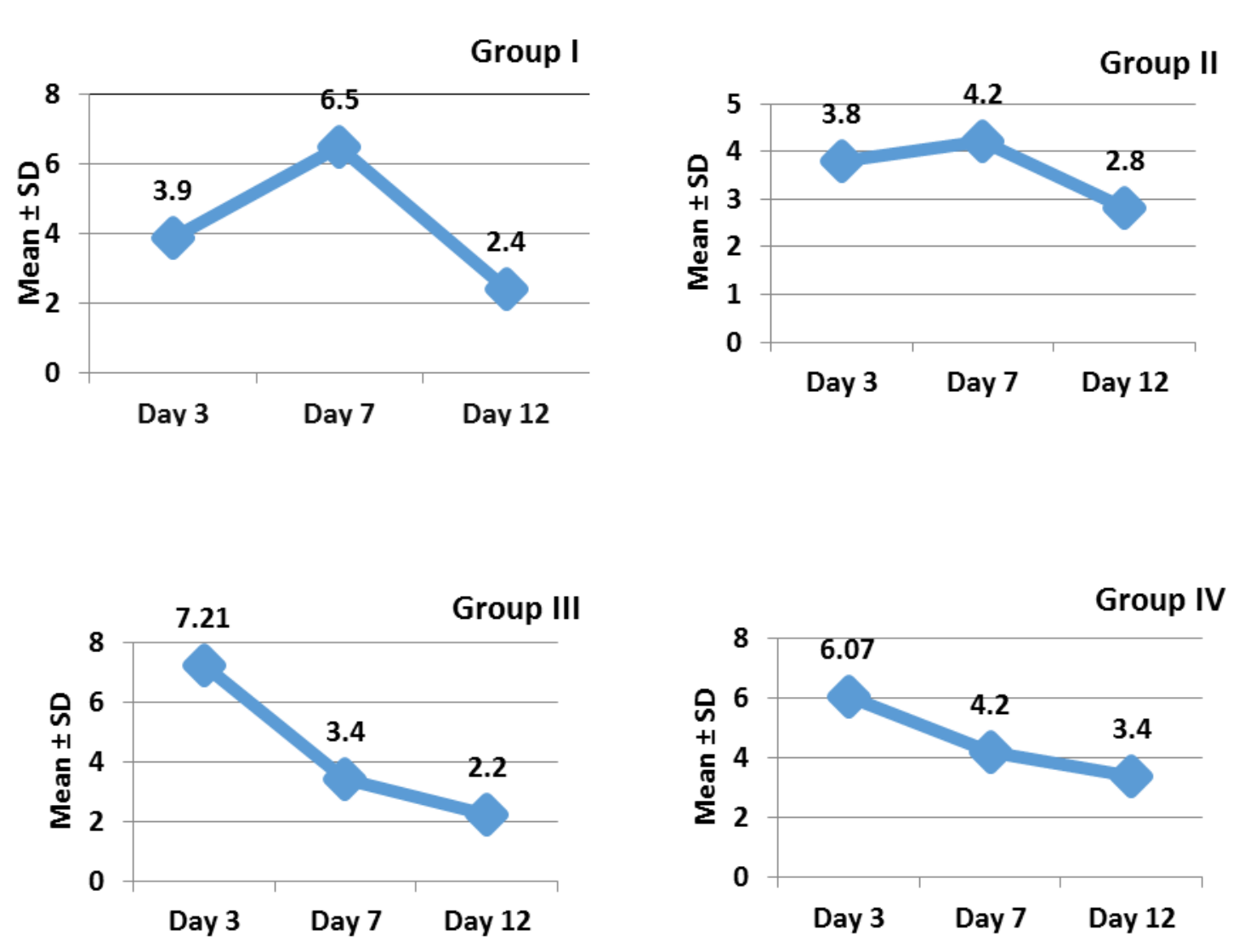

Figure 4:- Line charts shows mean \pm SD of PCNA expression in different studied groups at different sacrifice dates.

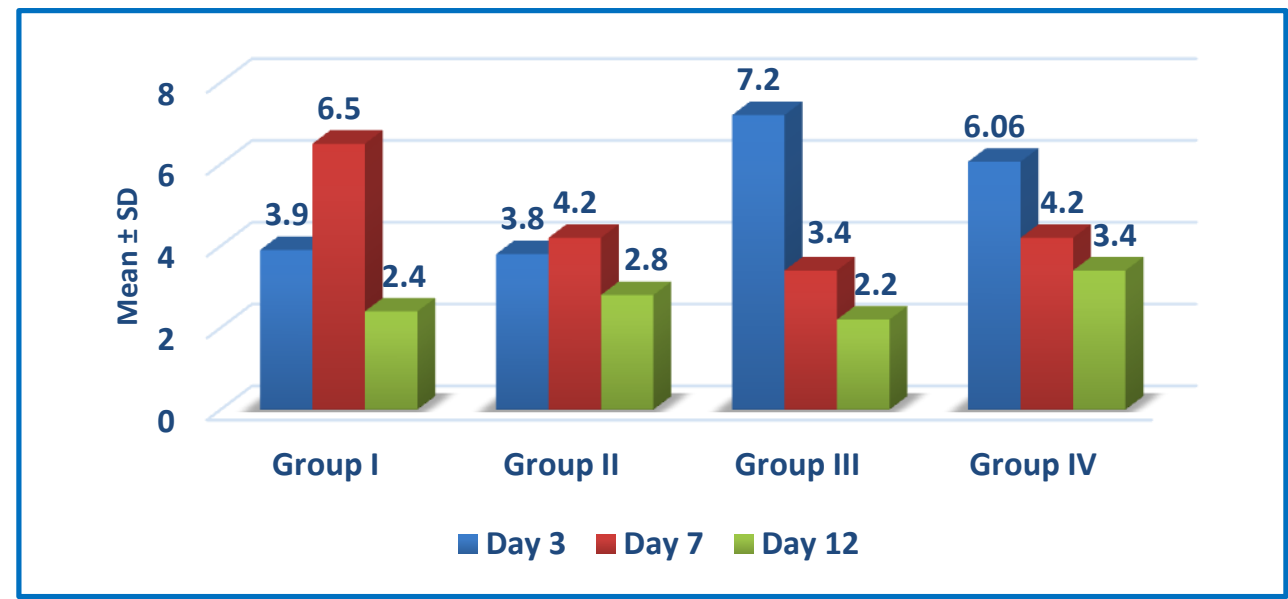

Figure 3:- Bar chart shows mean \pm SD of PCNA expression in the studied groups. 
Table 1: Shows mean \pm SD for proliferating cell nuclear antigen (PCNA) at days 3, 7 and 12 among the studied groups

\begin{tabular}{|c|c|c|c|c|c|}
\hline & Group I & Group II & Group III & Group IV & Significance \\
\hline Day 3 & $3.901 \pm 0.001^{\text {ab }}$ & $3.8 \pm 0.82^{\text {cd }}$ & $7.2 \pm 1.61^{\text {ac }}$ & $6.068 \pm 0.824^{\text {bd }}$ & $\begin{array}{c}\mathrm{F}=12.098 \\
\mathrm{P}=0.001^{* *}\end{array}$ \\
\hline Day 7 & $6.5 \pm 0.45^{\text {abc }}$ & $4.2 \pm 1.03^{\mathrm{a}}$ & $3.4 \pm 0.47^{\mathrm{b}}$ & $4.2 \pm 1.06^{\mathrm{c}}$ & $\mathrm{F}=11.023$ \\
& & & & $\mathrm{P}=0.001^{* *}$ \\
\hline Day 12 & $2.4 \pm 0.84$ & $2.8 \pm 0.68$ & $2.2 \pm 0.59^{\mathrm{a}}$ & $3.4 \pm 0.51^{\mathrm{a}}$ & $\mathrm{F}=2.418$ \\
& & & & $\mathrm{P}=0.117$ \\
\hline
\end{tabular}

F=One Way ANOVA

** High statistically significant

${ }^{\text {abcde }}$ Similar letters denote significant difference between groups using Post Hoc LSD test

\section{References:-}

1. Aly LA, El-Menoufy H, Sadeq HS, RagaeA,andSabry D. (2014): Efficiency of systemic versus intralesional bone marrow-derived stem cells in regeneration of oral mucosa after induction of formocresol induced ulcers in dogs. Dental research journal., 11:212-21.

2. Brem H and Tomic-Canic M. (2007):Cellular and molecular basis of wound healing in diabetes. The Journal of clinical investigation., 117:1219-22.

3. Borue X, Lee S, Grove J, Herzog EL, Harris R, Diflo T, et al.(2004): Bone marrow-derived cells contribute to epithelial engraftment during wound healing. The American journal of pathology., 165:1767-72.

4. Chung JK, Park TK, Ohn YH, Park SK,and Hong DS.(2011): Modulation of retinal wound healing by systemically administered bone marrow-derived mesenchymal stem cells. Korean journal of ophthalmology: KJO., 25:268-74.

5. Dash NR, Dash SN, Routray P, MohapatraS, andMohapatra PC. (2009): Targeting nonhealing ulcers of lower extremity in human through autologous bone marrow-derived mesenchymal stem cells. Rejuvenation Res., 12:359-66.

6. Enoch S, Moseley R, Stephens P, Thomas DW.(2008): The oral mucosa: a model of wound healing with reduced scarring. Oral Surgery., 1:11-21.

7. Fekrazad R, Mirmoezzi A, Kalhori KA, and Arany P.(2015):The effect of red, green and blue lasers on healing of oral wounds in diabetic rats.J PhotochemPhotobiol B., 148:242-5.

8. Garg S, Wang W, Prabath BG, Boerma M, Wang J, Zhou D, et al.(2014): Bone marrow transplantation helps restore the intestinal mucosal barrier after total body irradiation in mice. Radiation research., 181:229-39.

9. Hall PA and Woods AL.(1990): Immunohistochemical markers of cellular proliferation: achievements, problems and prospects. Cell and tissue kinetics., 23:505-22.

10. Hie M, Shimono M, Fujii K, and Tsukamoto I. (2007):Increased cathepsin K and tartrate-resistant acid phosphatase expression in bone of streptozotocin-induced diabetic rats. Bone., 41:1045-50.

11. M. Isakson,C. de Blacam,D. Whelan,A. McArdle,and A. J. P. Clover.(2015): Mesenchymal stem cells and cutaneous wound healing: current evidence and future potential. Stem cells international.,2015: 831095

12. Ishii A, Muramatsu T, Lee JM, Higa K, Shinozaki N, Jung HS, and Shibahara T. (2014): Expression of p75(NGFR), a Proliferative and Basal Cell Marker, in the Buccal Mucosa Epithelium during Reepithelialization. ActaHistochemCytochem., 47:145-53

13. Karavana Hizarcioglu SY, Sezer B, Guneri P, Veral A, Boyacioglu H, Ertan G, et al. (2011):Efficacy of topical benzydamine hydrochloride gel on oral mucosal ulcers: an in vivo animal study. International journal of oral and maxillofacial surgery., 40:973-8.

14. Karp JM and LengTeo GS. (2009): Mesenchymal stem cell homing: the devil is in the details. Cell stem cell., 4(3):206-16.

15. Giles T. S. Kirby, Stuart J. Mills, Allison J. Cowin, Louise E. Smith.(2015): Stem Cells for Cutaneous Wound Healing. Biomed Res Int.,2015:285869.

16. Kwon DS, Gao X, Liu YB, Dulchavsky DS, Danyluk AL, Bansal M, et al. (2008):Treatment with bone marrowderived stromal cells accelerates wound healing in diabetic rats. International wound journal.,5:453-63.

17. Lin CD, Allori AC, Macklin JE, Sailon AM, Tanaka R, Levine JP, et al.(2008):Topical lineage-negative progenitor-cell therapy for diabetic wounds. PlastReconstr Surg.,122:1341-51.

18. Liu Y, Dulchavsky DS, Gao X, Kwon D, Chopp M, Dulchavsky S, et al. (2006):Wound repair by bone marrow stromal cells through growth factor production. Journal of surgical research.,136:336-41. 
19. McFarlin K, Gao X, Liu YB, Dulchavsky DS, Kwon D, Arbab AS, et al.(2006): Bone marrow-derived mesenchymal stromal cells accelerate wound healing in the rats. Wound Repair Regen.,14:471-8.

20. McLaughlin PJ, ImmonenJA,andZagon IS.(2013): Topical naltrexone accelerates full-thickness wound closure in type 1 diabetic rats by stimulating angiogenesis. Experimental biology and medicine (Maywood, NJ).,238:733-43.

21. Muskhelishvili L, Latendresse JR, Kodell RL, and Henderson EB.(2003): Evaluation of cell proliferation in rat tissues with BrdU, PCNA, Ki-67(MIB-5) immunohistochemistry and in situ hybridization for histone mRNA. The journal of histochemistry and cytochemistry: official journal of the Histochemistry Society., 51:1681-8.

22. O'Loughlin A, Kulkarni M, Creane M, Vaughan EE, Mooney E, Shaw G, et al.(2013): Topical administration of allogeneic mesenchymal stromal cells seeded in a collagen scaffold augments wound healing and increases angiogenesis in the diabetic rabbit ulcer. Diabetes., 62:2588-94

23. Papaccio G, Pisanti FA, Latronico MV, AmmendolaE,andGaldieri M.(2000):Multiple low-dose and single highdose treatments with streptozotocin do not generate nitric oxide. Journal of cellular biochemistry.,77:82-91.

24. Paradells S, Zipancic I, Martinez-Losa MM, Garcia Esparza MA, Bosch-Morell F, Alvarez-Dolado M, et al.(2015): Lipoic acid and bone marrow derived cells therapy induce angiogenesis and cell proliferation after focal brain injury. Brain injury.,29:380-95.

25. Rai N, Suryabhan, Ansari M, Kumar M, Shukla V, and Tripathi K. (2005):Effect of glycaemic control on apoptosis in diabetic wounds. Journal of wound care., 14:277-81.

26. Rees DA and Alcolado JC.(2005): Animal models of diabetes mellitus. Diabetic medicine: a journal of the British Diabetic Association., 22:359-70.

27. Rodriguez-Menocal L, Shareef S, Salgado M, Shabbir A,and Van Badiavas E. (2015): Role of whole bone marrow, whole bone marrow cultured cells, and mesenchymal stem cells in chronic wound healing. Stem cell research \& therapy.,6:24.

28. Rajasekar R, Manokaran K, Rajasekaran N, DuraisamyG,andKanakasabapathi D. (2014):Effect of Alpiniacalcarata on glucose uptake in diabetic rats-an in vitro and in vivo model. Journal of Diabetes \& Metabolic Disorders., 13:1.

29. Siqueira MF, Li J, Chehab L, Desta T, Chino T, Krothpali N, et al. (2010):Impaired wound healing in mouse models of diabetes is mediated by TNF-alpha dysregulation and associated with enhanced activation of forkhead box O1 (FOXO1). Diabetologia.,53:378-88.

30. Sorrell JM and Caplan AI.(2010): Topical delivery of mesenchymal stem cells and their function in wounds. Stem cell research \&therapy., 1:30.

31. Takaichi S, Muramatsu T, Lee JM, Jung HS, Shinozaki N, Katakura A, et al.(2014): Re-epithelialization of the Buccal Mucosa after Alkaline Chemical Injury. Actahistochemica et cytochemica.,47:195-201.

32. Tarnawski A, Hollander D, Krause WJ, Dabros W, Stachura J, andGergely H.(1990): "Healed" experimental gastric ulcers remain histologically and ultrastructurallyabnormal. J ClinGastroenterol.,12:S139-47.

33. Tarnawski A, Stachura J, Krause WJ, Douglass TG, and Gergely H.(1991): Quality of gastric ulcer healing: A new emerging concept. J ClinGastroenterol.,13:S42-47.

34. Vaananen HK.(2005): Mesenchymal stem cells. Annals of medicine.,37:469-79.

35. Yadollah-Damavandi S, Chavoshi-Nejad M, Jangholi E, Nekouyian N, Hosseini S, Seifaee A, et al. (2015): Topical Hypericum perforatum Improves Tissue Regeneration in Full-Thickness Excisional Wounds in Diabetic Rat Model. Evidence-based complementary and alternative medicine.,2015:245328.

36. Yamaguchi Y, Kubo T, Murakami T, Takahashi M, Hakamata Y, Kobayashi E, et al.(2005):Bone marrow cells differentiate into wound myofibroblasts and accelerate the healing of wounds with exposed bones when combined with an occlusive dressing. The British journal of dermatology.,152:616-22.

37. Yeghiazarians Y, Zhang Y, Prasad M, Shih H, Saini SA, Takagawa J, et al. (2009):Injection of bone marrow cell extract into infarcted hearts results in functional improvement comparable to intact cell therapy. Molecular Therapy., 17:1250-6.

38. You HJ and Han SK.(2014): Cell therapy for wound healing. J Korean Med Sci., 29:311-9.

39. Yue Z, Jiang TX, WidelitzRB,andChuong CM. (2005): Mapping stem cell activities in the feather follicle. Nature.,438:1026-9. 